\title{
Is glucose metabolism in the atria in patients with atrial fibrillation due to inflammation or remodeling?
}

\author{
Ayaz Aghayev, $M^{a}$ \\ a Cardiovascular Imaging Program, Department of Radiology, Brigham and Women's Hospital, \\ Harvard Medical School, Boston
}

Received Dec 15, 2021; accepted Dec 16, 2021

doi: $10.1007 / \mathrm{s} 12350-021-02901-6$

\section{See related article, pp. 2824-2836}

Atrial fibrillation (AF) is the most common cardiac arrhythmia, affecting more than 33 million patients worldwide. ${ }^{1}$ Risk factors for AF are older age, male sex, coronary artery disease, diabetes mellitus, hypertension, obesity, smoking, obstructive sleep apnea, and family history of $\mathrm{AF}$ in a first-degree relative. ${ }^{2}$ A recently published, large multi-institutional study showed that among 10,723 newly diagnosed AF patients, $19 \%$ had an acute precipitant, and the most common causes were cardiac surgery, pneumonia, and noncardiac surgery. ${ }^{3}$ AF contributes to adverse outcomes by increasing the risk of stroke and reducing cardiac performance; it is also associated with an increased risk of death. ${ }^{4}$

AF could be paroxysmal, which terminates spontaneously within hours to days, or persistent, which usually requires electrical or pharmacologic cardioversion. ${ }^{4}$ The mechanism of AF is debated, but often in paroxysmal AF, trigger foci are commonly located along the pulmonary vein muscles; in persistent $\mathrm{AF}$, there is abnormal atrial substrate associated with fibrosis, electrophysiological changes in the myocytes, and dynamic modulating factors such as atrial stretch and autonomic tone. ${ }^{5}$ In the last decade, multiple studies have shown that inflammation plays a vital role in AF in addition to fibrosis, which is the major substrate in AF.

Reprint requests: Ayaz Aghayev, MD, Cardiovascular Imaging Program, Department of Radiology, Brigham and Women's Hospital, Harvard Medical School, Boston; Aaghayev@bwh.harvard.edu J Nucl Cardiol 2022;29:2837-8.

$1071-3581 / \$ 34.00$

Copyright ( 2022 The Author(s) under exclusive licence to American Society of Nuclear Cardiology
Local inflammatory diseases such as myocarditis or pericarditis are associated with a high incidence of AF. ${ }^{6}$ In a large study of patients with perioperative $\mathrm{AF}$, it was demonstrated that monocyte activation was increased. ${ }^{7}$ In the same study, the authors described that monocytes transform into long-lived tissue macrophages, which may also have a role in the inflammatory response leading to postsurgical AF. ${ }^{7}$ Other studies have evidenced a direct relationship between inflammation and AF. New-onset AF was observed more frequently in a study with critically ill patients and patients with sepsis. ${ }^{8}$ Additionally, there is a long list of possible inflammatory markers associated with AF. For example, a commonly known acute-phase protein, c-reactive protein (CRP), is increased in patients with AF. ${ }^{9}$ Another example is IL-1 $\beta$, which is secreted by activated macrophages and has been shown to be involved in pressure overload-induced AF. ${ }^{10}$

As imagers, we use diagnostic tools to localize inflammation in the body, particularly in the heart. For example, FDG-PET/CT has been utilized in diagnosing myocarditis or sarcoidosis. However, despite the increased number of studies regarding the association of inflammation and AF, imaging-related studies remain limited.

In this issue, Santi et al., for the first time, assessed altered atrial glucose uptake in patients with atrial fibrillation using standard cardiac FDG-PET/CT. They demonstrated a significant increase in FDG uptake in the right atrial free wall among those with AF compared to those without AF. Interestingly, they did not find a difference in left atrial free wall FDG uptake between patients with and without AF. They also found a significant correlation between FDG uptake and right atrial volume, and when accounting for atrial volume, the presence of AF remained a statistically significant predictor of higher right atrial FDG uptake. The authors did not find a relationship between left atrial FDG uptake 
and AF or left atrial volume. Consistent with this study, Fujii et al. evaluated 2367 cancer patients' PET studies (without using a dedicated cardiac PET or proper suppression) and demonstrated similar results. They found increased FDG uptake in the right atrium. ${ }^{11}$ Conversely, a study by Lange et al. found no abnormal FDG uptake in patients with $\mathrm{AF} .^{12}$ In their study, the limitations were as follows: (1) a small cohort of patients, (2) whole-body FDG-PET/CT for cancer screening was used, and (3) most importantly, they combined both paroxysmal and persistent AF patients together, potentially altering the results.

The authors discussed that focal inflammation in the RA is possible; however, given that it was only localized to one atrium, inflammation was less likely. They concluded that a more plausible explanation would be that there is altered glucose metabolism in the atrial myocardium. Additionally, they mentioned another hypothesis that left atrial FDG uptake could initially be increased at the beginning of AF and may potentially " "pseudonormalize", during the remodeling process, which is the more plausible explanation given the details above regarding the inflammation. A case study showed that a patient with paroxysmal AF had increased FDG uptake in both the left and right atria, which can support this idea. ${ }^{13}$ Unfortunately, this was only a case report, and there are no FDG-PET/CT studies to support this hypothesis.

In conclusion, I believe this study is important for demonstrating FDG uptake in the atrial wall in patients with AF. First, it is critical to be familiar with the FDG uptake pattern in the atrial wall in AF patients, as this is extremely important knowledge for routine clinical cardiac FDG-PET interpretations. Second, and most importantly, this study should increase interest regarding atrial FDG metabolism and eventually prompt studies to demonstrate in vivo temporal remodeling of both atria in AF patients. With this knowledge, management of $\mathrm{AF}$ could substantially change regarding medical treatment as well as the timing of catheter ablation.

\section{Disclosures}

The author has nothing to disclose.

\section{References}

1. Chugh SS, Havmoeller R, Narayanan K, Singh D, Rienstra M, Benjamin EJ. Worldwide epidemiology of atrial fibrillation: A
Global Burden of Disease 2010 Study. Circulation 2014;129:83747. https://doi.org/10.1161/CIRCULATIONAHA.113.005119[pub lishedOnlineFirst:20131217].

2. Staerk L, Sherer JA, Ko D, Benjamin EJ, Helm RH. Atrial fibrillation: Epidemiology, pathophysiology, and clinical outcomes. Circ Res 2017;120:1501-17. https://doi.org/10.1161/CIRCRE SAHA.117.309732.

3. Wang EY, Hulme OL, Khurshid S, Weng LC, Choi SH, Walkey $\mathrm{AJ}$, et al. Initial precipitants and recurrence of atrial fibrillation. Circ Arrhythm Electrophysiol 2020;13:e007716. https://doi.org/1 0.1161/CIRCEP.119.007716[publishedOnlineFirst:20200212].

4. Michaud GF, Stevenson WG. Atrial fibrillation. N Engl J Med 2021;384:353-61. https://doi.org/10.1056/NEJMcp2023658.

5. Fuster V, Ryden LE, Cannom DS, Crijns HJ, Curtis AB, Ellenbogen KA, et al. 2011 ACCF/AHA/HRS focused updates incorporated into the ACC/AHA/ESC 2006 Guidelines for the management of patients with atrial fibrillation: a report of the American College of Cardiology Foundation/American Heart Association Task Force on Practice Guidelines developed in partnership with the European Society of Cardiology and in collaboration with the European Heart Rhythm Association and the Heart Rhythm Society. J Am Coll Cardiol 2011;57:e101-98. h ttps://doi.org/10.1016/j.jacc.2010.09.013.

6. Zhou X, Dudley SC Jr. Evidence for inflammation as a driver of atrial fibrillation. Front Cardiovasc Med 2020;7:62. https://doi.org/ 10.3389/fcvm.2020.00062[publishedOnlineFirst:20200429].

7. Fontes ML, Mathew JP, Rinder HM, Zelterman D, Smith BR, Rinder CS, et al. Atrial fibrillation after cardiac surgery/cardiopulmonary bypass is associated with monocyte activation. Anesthesia Analgesia 2005;101:17-23. https://doi.org/10.1213/01. ANE.0000155260.93406.29.

8. Kuipers S, Klein Klouwenberg PM, Cremer OL. Incidence, risk factors and outcomes of new-onset atrial fibrillation in patients with sepsis: A systematic review. Crit Care 2014;18:688. https://doi. org/10.1186/s13054-014-0688-5[publishedOnlineFirst:20141215].

9. Dernellis J, Panaretou M. Effect of C-reactive protein reduction on paroxysmal atrial fibrillation. Am Heart J 2005;150:1064. https://d oi.org/10.1016/j.ahj.2005.06.032.

10. Matsushita N, Ishida N, Ibi M, Saito M, TakahashiTaniguchi MS, et al. IL-1beta plays an important role in pressure overload-induced atrial fibrillation in mice. Biol Pharm Bull 2019;42:543-6. h ttps://doi.org/10.1248/bpb.b18-00363.

11. Fujii H, Ide M, Yasuda S, Takahashi W, Shohtsu A, Kubo A, et al. Increased FDG uptake in the wall of the right atrium in people who participated in a cancer screening program with whole-body PET. Ann Nucl Med 1999;13:55-9. https://doi.org/10.1007/ BF03165430.

12. Lange PS, Avramovic N, Frommeyer G, Wasmer K, Pott C, Eckardt L, et al. Routine (18)F-FDG PET/CT does not detect inflammation in the left atrium in patients with atrial fibrillation. Int J Cardiovasc Imaging 2017;33:1271-6. https://doi.org/10.1007/ s10554-017-1094-2[publishedOnlineFirst:20170222].

13. Dong A, Zhao T, Gong J, Zuo C. Diffuse FDG uptake of the bilateral atrial walls in a patient with atrial fibrillation. Clin Nucl Med 2014;39:167-9. https://doi.org/10.1097/RLU.0b013e3182708 $94 \mathrm{c}$.

Publisher's Note Springer Nature remains neutral with regard to jurisdictional claims in published maps and institutional affiliations. 